\section{NFED OF STANDARDS OF TRAINING}

FOR SPECIALISTS, GENERAL PRACTITIONERS AND TEACIIERS OF SPEECH CORRECTION *

CHARLES G. STIVE்RS, M.D.

LOS ANGELES

Every one whose practice has anything to do with children realizes that the time is ripe for the development of a program for the study of the problems of defective speech, for about 5 per cent. of all children have some form of speech disorder. Institutions, boards of education and child welfare centers everywhere are asking for physicians to enlighten them on the prevention and correction of speech disorders.

Disorders of speech are increasing, partly because of the great revival of interest in education since the World War, as our system of public school training favors the production of more crowding, more psychoneuroses and more defects of all kinds, including speech disorders. Many foreigners in the larger cities who are learning to speak English at school are forced to speak their native language at home; t⿳亠丷厂犬is conflict often produces some form of speech defect. The World War has been followed by a large number of psychoneuroses, many with some form of speech defect, and this condition has helped to focus attention on the prevalence of speech disorders in adults, and compelled a better understanding of their frequency and importance.

There are about $1,000,000$ children with speech defects in the United States, and the problem is a serious one because these children must go to school while having corrective methods applied. But at present there is no agreement among teachers as to the best methods to use, and physicians are not yet, as a body, sufficiently qualified to establish standards of diagnosis, pathology, prognosis and treatment.

In the training of physicians to diagnose and treat these conditions, it is evident that some form of differentiation must be made in the amount and character of the training: 1. What shall the medical college offer the undergraduate? 2. What shall constitute or be considered an adequate amount of time to be devoted by a physician who wishes to become a specialist in speech, and of what particular subjects shall his training consist? 3. How shall teachers of speech correction be trained?

It is suggested that the premedical period of study should contain more psychology, introductory, general and genetic, with a survey of mental development in children and adolescents. Abnormal psycloology, including mental deficiency, truancy, mental measurements and the psychology of backward and abnormal children-there are 5,000,000 abnornal children in the United States, according to Lightner Witmer-must also be a part of the special training. Where in the curriculum these subjects can be introduced, in the premedical or undergraduate school, I do not attempt to say. That is a question for a committee to decide. I suggest only what I consider to be necessary training.

The specialist requires, in addition to general knowlclge, a much more intensive training than would be necessary for undergraduate students who should be required to know something about the diagnosis, prognosis and treatment of a case of disordered speech, but

* Read before the Section on Otology, Laryngology and Rhinology at the Seventy-Third Annual Session of the Anerican Medical Associaat the Seventy-Third Annual Session of the Anerican Medical Associa if Specch and the Use of Specch Drill in Orthopedic Cases." should not, unless specially trained and of proper original endowments, undertake the cure by corrective training methods. The specialist should be a physician who has had some special training in artistic voice and speech production, and in the diagnosis and treatment of the functional derangement as well as the pathologic conditions of the voice and speech producing organs. The present lack of competent advisers is responsible, in a large measure, for the great number of untrained voice teachers who ruin untold numbers of voices and cut short many a promising vocal career. There are many physicians whose language and temperament unfit them for special corrective work with children with speech troubles. For instance, a foreigner who speaks English with a foreign accent is not a good example for children to imitate. Especially is this true in cases of lisping, substitution and oral inactivity. The specialist should have had in his premedical training a thorough course in psychology, and, in his special work, he should become proficient in the diagnosis and treatment of the diseases of the nervous system, especially in children, and of the affections of the ear, nose and throat, since the psychology of speech is a linking together of the psychology of the phonatory, articulatory, respiratory and auditory systems. Because of the very large numbers of backward, subnormal and deficient children who have defective speech, the training in both normal and abnormal psychology is absoJutely necessary for the specialist.

The intelligence tests employed in the World War showed that 45 per cent. of those who were examined, or about one half of the total male population, had a mental capacity or natural ability that would never develop beyond the stage normal to a 12 year old child. They are doomed to remain forever subnormal. ${ }^{1}$ As there are many millions of our population who are mentally deficient, every medical graduate should be able to recognize mental deficiency in his practice, for several reasons, one of which is that a large number of subnormal persons have speech defects. It is essential that persons with speech clefects be graded mentally in order to do them justice in a social sense, so that the corrective methods applied to them, which may be followed by an anticipated result for speech training, will not be expected either to raise or to lower mental capacity. Medical schools should teach the relation of the teeth to phonetics, the rôle of dental irregularities, and the relation of malocclusion and cleft palate to language ability.

Recent studies reveal speech difficulties in the fields of orthopedics and pediatrics. My investigations show that there are twice as many cases of speech disorder among physically handicapped children as among normal children of school age. The speech training of these children will demand teachers who have special knowledge of physiotherapy and vocational guidance, and a comprehensive knowledge of the application of systematic training as a means of reaching mental levels. Teachers who wish to apply corrective methods should have the following qualifications:

1. They should be graduates of a normal school, college or university in which there was sufficient instruction in normal and abnormal psychology to prepare then for the understanding of the problems of defective speech.

2. They should be naturally endowed with an aptitude for handling nervous children.

\footnotetext{
1. Berman, Louis: The Glands Regulating Personality.
} 
3. They should be quick in auditory perception, should have well trained voices, and should be able to impart their knowledge to others.

4: They should be possessed of poise, patience and a love for the exacting demands of their careers.

5 . They should be trained in corrective gymnastics and be able to diagnose the commoner forms of bad posture, notably, faults in spinal alinement and foot and leg conditions, and they should be able to apply their knowledge of corrective exercises in the curing of respiratory and developmental faults.

6. They should understand phonetics both in the organic and the acoustic sense, and they should have some training in diction, dramatics, public speaking, elocution and class management.

We acknowledge the fact that it is better to prevent than to attempt to cure; so it is recommended that large cities have child welfare centers, preferably connected with; or the work supervised by a staff of, a university medical school or hospital. A speech clinic, as an integral part of such a center, should have as director a physician who has been trained as a specialist in the diagnosis and treatment of speech disorders. The consulting staff working with him should consist of specialists: a pediatrician a neuropsychiatrist an ophthalmologist an ear, nose and throat specialist; a dentist with special knowledge of orthodontia; an orthopedic surgeon, and an endocrinologist, who might also be the pediatrician.

Our language, English with American modifications, changes from generation to generation. A word may have one sound today and a totally different one in fifty years, or a modified sound in different parts of the United States, because there never can be any arbitrary standard for pronunciation for the whole country. Our aim, as speech defect specialists, must be to provide a standard of correct speech production, so that the children of today may have the ability to express their ideas in fluent English, and have no hesitation over word utterance. We must cooperate with boards of education to obtain these desired conditions. Accordingly, it would be wise to have a teacher of normal speech associated with a group of speech specialists. The corrective methods should be applied by assistants, either men or women, with the necessary natural endowments already referred to, trained in the practical application of corrective methods, including the reeducation of the deaf.

It will be necessary for those of the medical profession who are now trained as specialists of speech disorders to agree among themselves, after conferences, discussions and trials of methods, on a program for a comprehensive study of the entire field of oral expression. After this is accomplished, they must interest the men in the medical profession, as a body, by showing the need for a better understanding of the problems of defective speech, in a national campaign for better training of all physicians, specialists and teachers. When medical schools realize that the demand exists, they will inaugurate courses in this field, and the training of physicians in this specialty will no longer be subject to the criticism it now merits, because of its lack of recognized, accepted and practical standards. So-called schools which guarantee to cure speech defects, if the students live up to every one of the multitude of rules and restrictions, usually impossible to follow, will be replaced by standardized methods. The stammerer especially will be taught by reeducation and training to adapt himself to his home surroundings, not sent away to be "cured" and then returned to his home to become again a stammerer.

\section{SUMMARY}

The time is favorable to the development of a program, by the medical profession, for the study of the serious aspects of, and the correction of, speech disorders.

Five per cent. of all children have speech defects, calling for correction.

Speech defects are increasing, owing to revival of interest in primary education, with overcrowding, competition, psychoneuroses and foreigners.

The World War has produced many psychoneuroses; many with speech difficulties.

The orthopedic and psychiatric fields furnish many cases.

The medical profession, as a whole, is not qualified as yet to establish standards of speech correction.

It is necessary for those now trained in the theory and practice of speech correction to agree on standards, to begin a program of education of the men in the medical profession, and to secure cooperation of educators.

When medical colleges realize that a need exists, adequate facilities for training will be offered to undergraduates, specialists and teachers.

The nature and scope of the training must be determined by committees, conferences and discussions.

406 Auditorium Building.

\section{ABSTRACT OF DISCUSSION}

Dr. M. A. Goldstein, St. Louis: This is the first time I have ever had the opportunity of seeing corrective speech demonstrated when it could also be definitely studied with a slow motion camera. I was much impressed in Washington a few weeks ago at the work done experimentally on the labyrinth of animals and the splendid demonstration by the slow motion camera of the removal of the labyrinth under different conditions, and the action of the slow motion camera in the study of this unusual series of changed musculature. I congratulate Dr. Stivers on the philosophy he has presented in the relationship of individual spastic muscle conditions to the general muscle contraction that one finds in so many of the larger groups of crippled children. I should like to know what proportion of the patients Dr. Stivers examined have defects in speech. The medical man in his study of speech defects and their correction not only must consider the mechanical element of correction, but also ought to be a fairly universal specialist in the study of his cases. He must study the psychology; he must know anatomy, physiology and speech machinery; he must know the relation of breathing to the muscles of the mechanics of speech; he must know the peculiar adaptability of the defective child to its defects, and he must know the pedagogy with which these defects are definitely improved. It is not such an easy thing to go into a room where corrective speech patients are being given instruction, make a few observations, and go away feeling that one has studied the situation thoroughly. One cannot make an expert in handling corrective speech cases over night, any more than one can make an expert otologist over night. An expert, whether teacher or physician, should know anatomy, physiology and pathology, besides the mechanics that go into the correction of the speech defect.

Dr. Elmer L. Kenyon, Chicago: I have had a little experience with the spastic child with reference to the speech problem. The problem is prodigious, and I congratulate Dr. Stivers on having had the courage and intelligence even to attempt to tackle it on a large scale. I should like to ask him to state more definitely what results he is able to get with children who are distinctly spastic in the mouth region. Dr. Stivers' demonstration points clearly to the fact that speech disturbance is not a laryngologic problem alone. Dr. Goldstein 
hrought out that point. I venture to say that etiologically 90 per cent. of the cases of speech defect have their cause in the brain. They go into the field of the psychologist, the psychiatrist and the child specialist. If we focus our attention too closely on the mere treatment of disorders of speech, we may forget the larger problem, the distinctively medical problem, i. e., etiology and prevention. We are developiing a most interesting system in the public schools of treating defects of speech, a most valuable thing; and yet if we are not careful it will be so superficial that we shall have largely to do it over. The foundations of defects of speech have occurred long before the school age. These defects should usually be attacked when they are beginning. It seems to me that we as physicians should endeavor to strive to advance speech problems largely from an etiologic standpoint and a preventive standpoint, and that for the largest success the psychiatrist and the pediatrician must be brought definitely into the problem.

Dr. Dennis J. MCDonald, New York: Years ago I was one of the commissioners of education in New York ant introduced this work in public schools, and today I am much pleased and take new heart because of the work of James Sonnet Greene. He has founded a national hospital for the cure of speech defects. This is a wonderful demonstration we have had today. It is a work for the nation, and for the women.

Dr. Louis K. Guggenhela, St. Louis: I want to subscribe most heartily to the statement that this is a tremendously important subject; but I want also to sound a note of warning. This work is not for the otolaryngologist. A few years ago, feeling the necessity for some one to do something for these patients, I went to Europe to study the subject, naively ignorant of the size of the problem. I was going to practice otolaryngology, and in my spare time treat speech cases. I opened a clinic at Washington University, and had a sign painted "Speech Defects." Being connected with the ear department, I could spare only three afternoons a week for the speech clinic. I had two patients to begin with; the next week there were five, the next ten, then fifteen and finally I was overwhelmed. This was not because I knew anything about speech defects, but simply because so many persons were afflicted. The thing became a Frankenstein monster, and I had to give it up. The treatment of speech cases is not for otolaryngologists, and I doubt very much whether it is for physicians at all. It is a woman's job. We have neither the patience nor the time. I think that Dr. Goldstein has really solved the problem. and he certainly deserves the support not only of St. Louis but also of the whole country. This demonstration may give an erroneous impression. There are thousands of cases of spastic speech defects that have nothing to do with general spastic conditions; also these patients impressed me as being mentally subnormal children. There are innumerable bright persons who are stutterers, and thousands of orthopedic patients that have no speech defects.

DR. J. A. Stucky, Lexington, Ky.: Laryngologists have been using too many sprays and too much electricity in the larynx for the correction of speech defects, when the trouble was not there. I should like to ask the author about one point, in which I am much interested, and that is about the endocrine insufficiency. What test did he make to determine this? My cxperience has been that we usually find hypopituitary and hypothyroid conditions, but I am not satisfied with the tests I am making.

Dr. Charles G. Stivers, Los Angeles: Not knowing anything about endocrinology, but having in my office an endocrinologist, I turn these patients over to him and he gives them proper examination and treatment. We have in this series two or three cases of endocrine dysfunction, and they are hypothyroid and hypopituitary cases. I limited my statements about speech to the fact that speech production proceeded from stored muscle memories. I did not say that speech began with the motor areas. I said that one can move a muscle only if one has an inherent muscle memory which has been stored in the brain at some previous time. A clearing up of most of the questions will be found in the paper itself, which I did not read. The paper itself is an academic discussion of the need for education of physicians and others wiro are to take up the work. This film is a practical dem- onstration of the application. I heartily agree with what Dr. Goldstein said. In the whole treatment of the spastic child I refer to the child who has other expressions of spasticitynot the spastic stutterer, which is a purely central manifestation. The case is first approached by the orthopedic surgeon to make a diagnosis and apply corrective treatment-operations, surgical dressings, braces, etc.-and to get the child into proper condition in which it can be given these exercises for the building up of muscle tone. One of the best results we obtain in the treatment of the mouth and throat is the disappearance of the drooling. This disappears when we build up the tonicity of the mouth muscles. The work is so new and has gone on such a short time that we are not able to state definitely what we can do except with the vowels. We have worked very little with the consonants, because the spastic cases tend to overact and we do not wish to pursue any line of treatment or exercise that would call for any more exercise of the muscles than is absolutely necessary. The speech defect specialist is not only an otologist. He also needs training in otolaryngology and ophthalmology, because speech may be both written and heard. There is also a lot of psychology and neuropsychiatry and pediatrics, as well as study of how to produce articulation that can be interpreted by others, and there one has the problem of knowing something about pedagogy. I am perfectly willing to have young women of the right personality and manner to do the training and merely act as adviser, leaving this active treatment work to the young women themselves.

\section{IS DEATH IN HIGH INTESTINAL OBSTRLCTION DUE TO LIVER INSUFFICIENCY?*}

AXEL WERELIUS, M.D. CHICAGO

Death in acute intestinal obstruction is almost generally conceded to be due to a toxemia derived from absorption of toxic products accumulated in the intestine above the obstruction. The higher the obstruction, the greater the supposed toxicity, and the more rapid the fatal issue. In order to examine this toxic material, segments in various parts of the intestine have been tied or sectioned off. The results are practically the same as in ordinary obstruction.

If the duodenum in a $\operatorname{dog}$ is ligated, or sectioned above and below, the animal dies in from twenty-four to forty-eight hours. For several hours subsequent to the operation (sometimes twenty-four hours) the animal shows nothing abnormal; then the symptoms are ushered in rather suddenly with signs of increasing weakness and extreme sluggishness. There is no restlessness, no irritability, no convulsions. The animal lies down and refuses to come when called. It does not seem to suffer. As a rule, after twenty-four hours the temperature becomes subnormal with increased pulse and respiratory rate. Very rarely is there any vomiting, and then only after something has been eaten. Constipation is complete. The outstanding feature is a progressive asthenia.

Death, then, occurs very rapidly and, as above, is thought to be due to absorption of highly toxic products in the loop of the duodenum. If this were the true explanation, there would be some excuse for reasoning that if these toxic products would be drained out of the loop of the duodenum, the life of the animal, if not saved, would at least be somewhat prolonged or, in other words, death would be delayed. However, in

* From the South Shore Hospital Laboratory.

* Read before the Section on Obstetrics, Gynecology and Abdominal Surgery at the Seventy-Third Annual Session of the American Medical Association, St. Louis, May, 1922. 